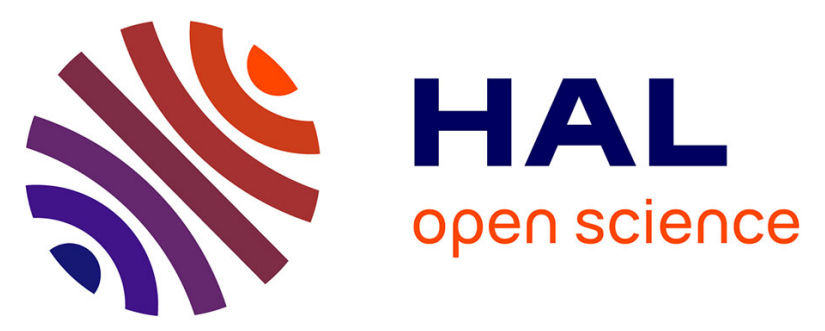

\title{
High promoter methylation levels are predictive of poor prognosis in fine-needle aspirate washings of breast cancer lesions
}

Ana Teresa Martins, Paula Monteiro, João Ramalho-Carvalho, Vera L. Costa, Mário Dinis-Ribeiro, Conceição Leal, Rui Henrique, Carmen Jerónimo

\section{To cite this version:}

Ana Teresa Martins, Paula Monteiro, João Ramalho-Carvalho, Vera L. Costa, Mário Dinis-Ribeiro, et al.. High promoter methylation levels are predictive of poor prognosis in fine-needle aspirate washings of breast cancer lesions. Breast Cancer Research and Treatment, 2010, 129 (1), pp.1-9. 10.1007/s10549-010-1160-0 . hal-00615378

\section{HAL Id: hal-00615378 https://hal.science/hal-00615378}

Submitted on 19 Aug 2011

HAL is a multi-disciplinary open access archive for the deposit and dissemination of scientific research documents, whether they are published or not. The documents may come from teaching and research institutions in France or abroad, or from public or private research centers.
L'archive ouverte pluridisciplinaire HAL, est destinée au dépôt et à la diffusion de documents scientifiques de niveau recherche, publiés ou non, émanant des établissements d'enseignement et de recherche français ou étrangers, des laboratoires publics ou privés. 
High RASSF1A promoter methylation levels are predictive of poor prognosis in fineneedle aspirate washings of breast cancer lesions

Ana Teresa Martins ${ }^{1,2}$, Paula Monteiro ${ }^{2}$, João Ramalho-Carvalho ${ }^{1,3}$ Vera L. Costa ${ }^{1,3}$, Mário Dinis-Ribeiro $^{4,5}$, Conceição Leal ${ }^{2}$, Rui Henrique ${ }^{1,2,6}$, Carmen Jerónimo ${ }^{1,3,6}$

${ }^{1}$ Cancer Epigenetics Group, Research Center of the Portuguese Oncology Institute - Porto; Departments of ${ }^{2}$ Pathology, ${ }^{3}$ Genetics, and ${ }^{4}$ Gastroenterology, Portuguese Oncology Institute - Porto, Portugal

${ }^{5}$ Department of Biostatistics and Medical Informatics, Faculty of Medicine, University of Porto, Portugal

${ }^{6}$ Department of Pathology and Molecular Immunology, Institute of Biomedical Sciences Abel Salazar (ICBAS), University of Porto, Portugal

\section{Reprint requests:}

Carmen Jerónimo, PhD

Department of Genetics

Portuguese Oncology Institute - Porto,

Rua Dr. António Bernardino de Almeida, 4200-072 PORTO.

E-mail: carmenjeronimo@ipoporto.min-saude.pt

Telephone: +351225084000

Fax: +351 225084016 


\section{ABSTRACT}

Purpose: Previously, we reported that the accuracy of cytological diagnosis of breast lesions could be augmented through the quantitative assessment of DNA methylation of fine-needle aspirate (FNA) washings. Herein, we aimed at the evaluation of the prognostic value of quantitive promoter methylation at three gene loci ( $A P C, C C N D 2$, and RASSF1A) in a large series of FNA washings from breast lesions.

Experimental design: Methylation levels of three gene promoters were assessed by quantitative methylation-specific PCR in bisulfite-modified DNA from 211 FNA washings, comprising 178 carcinomas and 33 benign lesions, both histopathologically confirmed. Receiver operator characteristic $(\mathrm{ROC})$ curve analysis was used to determine the diagnostic performance of the gene panel in distinguishing cancer from non-cancerous lesions. Relevant clinicopathologic data and time to progression and/or death from breast cancer were correlated with methylation findings. Log-rank test and Cox regression model identified independent predictors of prognosis.

Results: $A P C, C C N D 2$, and RASSF1A methylation levels differed significantly between malignant and benign lesions. ROC curve analysis confirmed the diagnostic performance of the gene panel. In univariate analysis, stage was significantly associated with overall, disease-specific and disease-free survival, whereas tumor grade was associated with disease-specific and disease-free survival. Remarkably, RASSF1A methylation was significantly and independently associated with worse disease-free survival in the final multivariate analysis.

Conclusions: We confirmed that quantitative gene promoter methylation augments the diagnostic performance of cytopathology. Importantly, and in addition to standard clinicopathologic parameters, RASSF1A high-methylation levels are independent predictors of worse outcome in breast cancer. Thus, epigenetic biomarkers provide valuable tools for breast cancer patient management.

Key words: breast cancer, quantitative DNA methylation, epigenetic profile, fine needle aspirates, prognosis 


\section{INTRODUCTION}

Among all female cancers diagnosed worldwide in 2008, breast cancer accounted for $23 \%$ of cases, being the most common cancer in women, with an estimated 1.34 million new cases that year [1]. For 2009 in the United States, breast cancer is expected to account for $27 \%$ (192 370) of all new cancer cases in women, representing the second most deadly cancer, being responsible for 15\% (40 170) of all cancer deaths in women in the same period [2]. Thus, breast cancer constitutes a major health concern and continuous efforts are required to lower the mortality and morbidity rates associated with the disease.

Although ultrasound-guided breast biopsy is usually employed for breast cancer diagnosis, fine needle aspiration (FNA) biopsy of suspicious breast lesions provides a relatively simple, minimally invasive and rapid mean of triaging patients to more complex diagnostic procedures [3]. Because the accuracy of FNA largely depends on the cytopathologist proficiency both in performing the aspirate and the cytomorphological analysis [3-4] and the identification of small pre-invasive lesions and well-differentiated tumors may be challenging [5], analyses of tumor associated DNA alterations could augment the accuracy of the evaluation of cellular morphology [3].

Alterations in the methylation status of DNA are amongst the most frequent molecular changes associated with human cancers [6]. The search for genes in which promoter CpG islands are hypermethylated in cancer has been increasing, revealing unique profiles of hypermethylation that define each neoplasia. Because DNA methylation is linked to tissuespecific gene silencing [6], and methylation may, therefore, be used as a biomarker for cancer. For instance the GSTP1 gene is hypermethylated in 80 to $90 \%$ of patients with prostate cancer, but rarely in benign prostate tissues [6-7].

The list of aberrantly methylated genes identified in breast cancer is long, covering most aspects of their biological functions: cell cycle regulation, apoptosis, DNA repair, hormone regulation, cell adhesion and invasion, angiogenesis, cellular growth-inhibitory signaling, 
among other [8-10]. In breast cancer, methylation patterns have been developed as biomarkers for early detection and subtype classification, as risk stratifiers, for monitoring prognosis, and as predictors of susceptibility or response to therapy [6, 10]. Recently, we reported that a defined methylated gene panel augments the accuracy of breast cancer detection in FNA washings [9]. Herein, we extended those observations and sought to determine whether quantitative promoter methylation of three gene loci included in the breast cancer detection panel might also carry prognostic information in addition to standard clinicopathologic parameters. These results could provide a supplementary ancillary tool to evaluate tumor aggressiveness and aid in therapeutic decision. 


\section{PATIENTS AND METHODS}

\section{Patients, sample collection, and DNA extraction}

A total of 237 female patients with palpable suspicious breast lesions, consecutively submitted to FNA at the Portuguese Oncology Institute - Porto, Portugal, from 2002 to 2008, were enrolled in this study, following informed consent. Relevant clinical and pathological data was retrieved from the patient's clinical records. These studies were approved by the institutional review board (IRB) of Portuguese Oncology Institute - Porto.

FNA biopsy was performed pre-operatively using a 23-gauge needle attached to a $10-\mathrm{ml}$ syringe and inserted into a syringe holder. The aspirates were smeared on microscope slides and routinely stained for cytopathological evaluation. Samples for methylation analysis were produced by washing the needle and syringe with $250 \mu \mathrm{l}$ of phosphate buffer saline. The solution was spinned down, and the pellet was collected in a tube and stored at $-80^{\circ} \mathrm{C}$. DNA extraction was performed as previously described [3].

All the tumors were classified [11] and graded according to Bloom and Richardson's Modified system [12] by the same pathologist, and staged according to the AJCC system [13].

\section{Bisulfite treatment and QMSP}

This method allows for the assessment of the methylation status of individual $\mathrm{CpG}$ islands in genomic DNA. Sodium bisulfite conversion of unmethylated cytosine residues to uracil of genomic DNA obtained from FNA washings samples was performed as described previously (14]. The modified DNA was then used as a template for QMSP. Three promoters from genes involved in cell cycle regulation [Cyclin D2 (CCND2], apoptosis [Ras association domain family protein $1(R A S S F 1 A$ ] and cell signaling [Adenomatous polyposis coli $(A P C)$ ], were assessed, using primers and probes described elsewhere (15-16].

To determine the relative levels of methylated promoter DNA in each sample (methylation level, $\mathrm{ML}$ ), the values obtained for each target gene were compared with the values of the 
internal reference gene. The ratio was then multiplied by 1000 for easier tabulation $([\mathrm{ML}=$ (target gene/ACTB) x 1000]. Fluorogenic QMSP assays were carried out in a reaction volume of $20 \mu \mathrm{L}$ in 96-well plates in an Applied Biosystems 7000 Sequence Detector (Perkin Elmer, Foster City, CA). PCR was performed in separate wells for each primer/probe set and each sample was run in triplicate. Additionally, multiple water blanks were used per plate, as previously detailed [17] and also a serial of dilutions of a positive control for constructing the corresponding calibration curve.

A given sample was considered positive when amplification was detected in at least two of the triplicates of the respective QMSP analysis. The QMSP threshold was determined adjusting the best fit of the slope and $\mathrm{R} 2$ based on the respective calibration curve.

\section{Statistical analysis}

The frequency of methylated and unmethylated cases, as well as the median and interquartile range of the methylation level for each gene in each group of tissue samples was determined. Methylation levels of the genes were expressed as continuous variables. Values were analyzed using non-parametric tests, i.e., the chi-square test and the MannWhitney $U$ test, to compare methylation frequencies and levels, respectively, between malignant and benign lesions. Receiver operator characteristic (ROC) curve analysis was used for each gene to determine the respective diagnostic performance, using the Area under the Curve [AUC, with 95\% confidence interval $(\mathrm{CI})]$. This analysis was performed for all cases and also separately for premenopausal and postmenopausal cancer cases. Histopathologic evaluation constituted the gold standard or reference test. Positivity for each methylated promoter was set as previously determined [9] and quantitative estimates of validity were determined.

The prognostic significance of clinical and pathological variables (age, tumor grade, pathological stage and hormone receptor status) was assessed by constructing overall, disease-specific and disease-free survival curves using the Kaplan-Meier method with log rank test (univariate test), and by a Cox-regression model comprising all variables 
(multivariate test). To test the prognostic significance of the methylation status for each gene, samples were categorized into two groups based on the methylation levels for that gene, using as threshold the value of the percentile 75 [18]. Overall, disease-specific and diseasefree survival curves were then constructed based on each of the three genes (univariate analysis). A Cox-regression model comprising both clinical and epigenetic variables was then computed to assess the relative contribution of each variable to the assessment of follow-up status.

A P value smaller than 0.05 (two-sided) was considered to indicate statistical significance. Statistical analyses were carried out using a computer-assisted program (SPSS, version 11.0, Chicago, IL). 


\section{RESULTS}

\section{Clinical and pathological data}

We tested FNA washing samples from 237 suspicious breast lesions, 148 of which were cytopathologically diagnosed as malignant and 37 as benign. In the remaining 52 cases no definitive cytomorphological diagnosis was rendered (this category includes cases reported as "suspicious", "inconclusive", and "insufficient material").

Histopathological material for examination was available in 211 cases, comprising 178 malignant and 33 benign lesions. The relevant clinical and pathological characteristics of these patients are provided in Table 1 . Of these 211 cases, 123 have been included in a previous study [9].

\section{QMSP in breast cancer and non-cancerous breast tissues}

QMSP was performed only in the 211 FNA washings in which a confirmatory histopathological diagnosis was available. The methylation frequencies and distribution of methylation levels are listed in Table 2. The frequency of promoter methylation was higher in malignant lesions for all genes, although a statistically significant difference was only observed for $A P C(P=0.003)$. Breast cancers also displayed the highest methylation levels for all the analyzed genes (Table 2).

\section{Performance of methylation markers in FNA washings}

The diagnostic performance of the three genes was assessed using the cutoff values of methylation levels previously determined for each of these gene promoters (5.0 for APC, 2.0 for CCND2, and 50.0 for RASSF1A) [9]. ROC curve analysis allowed for the determination of the AUC $(\mathrm{Cl})$ for each gene: $0.74(0.66-0.82)$ for $A P C, 0.76(0.68-0.83)$ for $C C N D 2$, and 0.72 (0.63-0.81) for RASSF1A (Figure 1). Additionally, this analysis was performed independently for pre- and postmenopausal women (Figures $2 \mathrm{~A}$ and 2B, respectively). The AUC (CI) for each gene was: $0.73(0.62-0.85)$ for $A P C, 0.69(0.57-0.81)$ for $C C N D 2$, and 0.62 (0.49-0.76) 
for RASSF1A, for premenopausal women, and $0.82(0.70-0.93)$ for $A P C, 0.86(0.79-0.92)$ for CCND2, and 0.87 (0.81-0.94) for RASSF1A, for postmenopausal women.

Considering the above mentioned cutoff values for each gene, 123 (69\%), 134 (75\%), and $134(75 \%)$ of malignant samples were positive for APC, CCND2, and RASSF1A, respectively, whereas 8 (24\%), $14(42 \%)$, and $13(39 \%)$ of benign samples were positive for $A P C, C C N D 2$, and RASSF1A, respectively. Validity and information estimates considering one, two or three positive markers are displayed in Table 3. The best balance between sensitivity and specificity was obtained with two positive markers $(0.78$ and 0.79 , respectively).

\section{Correlations between epigenetic data and clinicopathological parameters}

Table 4 depicts the distribution of methylation levels for each gene according to standard clinicopathological parameters. No significant correlations were found between promoter methylation levels and patients' age, tumor grade or pathological stage. However, statistically significant differences were observed for RASSF1A and CCND2 methylation levels between estrogen receptor positive and estrogen receptor negative breast tumors $(P=0.003$ and $P<$ 0.001, respectively). Moreover, a statistically significant difference was observed for CCND2 methylation levels concerning progesterone receptor status $(P=0.011)$.

\section{Survival analyses}

The median follow-up of this series of breast cancer patients $(n=178)$ was 57.7 months (range: 0.5 to 90 months). A total of 19 patients (10.7\%) died from breast cancer during the follow-up period and $13(7.3 \%)$ patients were lost to follow-up. For the purposes of survival analyses, all cases were coded based on gene methylation levels using as a threshold the value of percentile 75 for each gene. Moreover, grade 1 and 2 tumors were coupled in the same category, against grade 3 tumors. Among all clinical, pathological, and molecular variables analyzed, increased pathological stage, tumor grade, and high-methylation levels of RASSF1A were associated with worse overall survival in univariate analysis $(\mathrm{P}<0.001, \mathrm{P}$ 
$=0.018$, and $P=0.040$, respectively). Disease-specific survival curves using established clinical and pathological variables showed that advanced pathological stage and tumor grade were significantly associated with a worse outcome $(P<0.001$ for both) (Figures 3 and 4$)$, whereas age, hormone receptor status and gene methylation levels did not show prognostic value within the available follow-up time.

Tumor recurrence was detected in $32(18.0 \%)$ patients during the follow-up period. Advanced clinical stage, increased tumor grade, and high-methylation levels of RASSF1A (Figure 5) were significantly associated with disease relapse in univariate analysis $(P<0.001, P<$ 0.001 , and $P=0.004$, respectively).

When clinical and epigenetic variables were introduced in a Cox-regression model for the prediction of relapse, pathological stage, tumor grade, and RASSF1A methylation levels were selected in the final step of the model as independent predictors (Table 5). 


\section{DISCUSSION}

Cytological evaluation of suspicious breast lesions has been widely performed as an initial triaging procedure to identify malignant lesions and assist the clinician in setting the best strategy to obtain a definitive diagnosis and subsequent therapeutic decisions. However, cytomorphological assessment of breast FNA biopsy specimens meets with important limitations ranging from the cytopathologist's proficiency to the availability of representative material to render a definitive diagnosis. In previous studies, we demonstrated that FNA washings from suspicious breast lesions yield significant amounts of genomic DNA for methylation studies [3] and we confirmed the power of a small panel of methylation markers to identify malignant breast cells even in cases with low yield of cytological material, thus providing a valuable ancillary tool to routine cytomorphological observation [9]. In this study, we extended the spectrum of analysis of epigenetic markers in breast cancer, assessing the prognostic value of quantitative gene promoter methylation in a large series of breast cancer patients.

Overall, the population on which this study is based reflects the referral condition of a cancer institute. Indeed, benign lesions are less than $20 \%$ of all cases analyzed as most patients had been already triaged by the respective general physician based on clinical and imagiological information. Thus, most cases were highly suspicious of cancer and that condition was confirmed by FNA biopsy in the vast majority of cases. This finding highlights the usefulness of the FNA biopsy procedure, although in $22 \%$ (52 out of 237 ) of cases no definitive diagnosis was rendered based on cytomorphological evaluation.

The present series includes 123 of the cases previously reported by our research group [9] and it was extended with new consecutive cases, almost doubling the original series. This larger series of patients allowed us to perform a confirmatory test of the diagnostic performance of the small panel of methylation markers previously reported to augment the accuracy of FNA biopsy of breast lesions [9]. However, of the initial panel of four genes, only three loci were analyzed $(A P C, C C N D 2$, and RASSF1A) owing to the scarcity of DNA 
available for each sample. Importantly, from our previous findings we concluded that two or three methylation markers would provide adequate ancillary information for breast cancer diagnosis in FNA biopsies [9]. In the present series, ROC curve analysis confirmed our previous findings concerning the diagnostic performance of individual methylation markers. Interestingly, the validity estimates indicate that the best balance between sensitivity and specificity (around $80 \%$ for both) was obtained when two positive markers were used to identify a malignant lesion. It is noteworthy that we used the same cutoff values for gene methylation levels previously determined [9], a feature that provides additional validity to the present results.

The cancer specificity of our three gene panel is well demonstrated in the present study as the median levels of methylation at APC, CCND2, and RASSF1A promoters differed significantly between cancerous and non-cancerous samples, confirming our previous observations [9]. Importantly, these results are also in accordance with the findings of other researchers. Pu and co-workers reported on the ability of RAR $\beta, R A S S F 1 A$, and CCND2 promoter methylation to identify malignancy in FNA samples with indeterminate cytological diagnosis [19]. Moreover, aberrant methylation in at least one of a three gene panel which included RASSF1A, APC, and DAPK1 was positive in $76 \%$ of serum samples from breast cancer patients [20]. These studies confirmed the usefulness of epigenetic markers for early and accurate detection of breast cancer, in parallel with similar findings from our research group and others concerning prostate cancer [21].

The statistically significant age difference between patients carrying benign or malignant lesions might be one of the limitations of this study. However, there is a substantial overlap between the two groups (18 to 77 years vs. 29 to 92 years, respectively). Although associations between gene promoter methylation and age have been reported, they are not a universal finding and results are even conflicting concerning breast tissues. Whereas some researchers found age related variations for RASSF1A, with an odd pattern of increase from 32 to 55 years with a decline thereafter [22], other studies did not find such a correlation [23]. Moreover, no correlation between age and $A P C$ or CCND2 promoter methylation has been 
reported thus far [22, 24]. Finally, in the present study no association between age and methylation levels was apparent for any of the genes. Therefore, it is unlikely that age distribution is inducing significant bias in the performance of the epigenetic biomarkers.

The main novelty of this study, however, lies on the assessment of the prognostic value of methylation markers quantitatively determined in FNA washings from breast lesions. Indeed, to the best of our knowledge, this is the first study to demonstrate that high-methylation levels of the RASSF1A promoter (> p75) assessed in FNA washings is an independent predictor of poor outcome in breast cancer patients. The cutoff value (p75) was based in our previous studies in prostate cancer which demonstrated that high-methylation levels of $A P C$ were independent predictors of poor outcome [18]. The biological rationale for the use of this cutoff is based on the association between promoter methylation (evaluated in the present study) and gene expression, as this depends on the density of CpG dinucleotide methylation. Thus, it is expectable that cases with the highest levels of methylation (e.g., > p75) will have the lowest levels of mRNA expression, and, thus, gene silencing will be more effective in this subgroup. Consequently, the loss of RASSF1A function will likely increment tumor aggressiveness and might justify the poorer prognosis. Remarkably, RASSF1A promoter methylation has been previously identified as a potential prognostic marker for breast cancer in different types of clinical samples. Indeed, Muller and co-workers reported that RASSF1A promoter methylation detected in sera or plasma from patients with primary or metastatic breast cancer was associated with poor outcome [25]. Following the same line of evidence, Hoque and co-workers found that RASSF1A promoter methylation was more frequent in advanced stage breast cancer patients [26]. Interestingly, RASSF1A promoter methylation seems to be one of the earliest epigenetic alterations in breast carcinogenesis as it has been found even in benign, yet atypical, breast lesions and carcinoma in situ [16]. Thus, it would be tempting to speculate whether those lesions with higher RASSF1A methylation levels would be more prone to progress to invasive cancer.

The only clinicopathological parameters that surfaced as independent predictors of outcome in the present series were pathological stage and tumor grade, whereas hormone receptor 
status did not. This was a somewhat unexpected result as the expression of estrogen and/or progesterone receptor is associated with favorable prognosis and it is highly predictive of response to endocrine treatment [21]. Because no selection bias was apparent in our series, this lack of prognostic value for hormone receptor status might be due to insufficient followup time. We also did not assess HER2 status in the present series as a significant number of cases were collected prior to the implementation of routine HER2 assessment in breast cancer at our institution and, thus, that information was not available in many cases. Nonetheless, it is noteworthy that a molecular assay (quantitative RASSF1A promoter methylation) performed in an exiguous sample of cancer cells obtained by FNA was able not only to discriminate malignant from benign lesions, but also to convey relevant prognostic information when compared with standard parameters which require extensive tissue sampling and expert observation.

Further studies addressing the development of predictive models for pre-operative staging and therapy response based on epigenetic biomarkers might also provide valuable tools for breast cancer patient management.

\section{Acknowledgements:}

V.L.C is supported by a grant from Fundação para a Ciência e a Tecnologia (SFRH/BD/23374/2005).

This study was funded by grants from Liga Portuguesa contra o Cancro - Núcleo Regional do Norte and the Comissão de Fomento da Investigação em Cuidados de Saúde - Ministério da Saúde (Project no. 21/2007). 


\section{References}

1. Ferlay J, Parkin DM, Steliarova-Foucher E. Estimates of cancer incidence and mortality in Europe in 2008. Eur J Cancer. Mar;46(4):765-81.

2. Jemal A, Siegel R, Ward E, Hao Y, Xu J, Thun MJ. Cancer statistics, 2009. CA Cancer J Clin. 2009 Jul-Aug;59(4):225-49.

3. Jeronimo C, Costa I, Martins MC, Monteiro P, Lisboa S, Palmeira C, et al. Detection of gene promoter hypermethylation in fine needle washings from breast lesions. Clin Cancer Res. 2003 Aug 15;9(9):3413-7.

4. Nemec CF, Listinsky J, Rim A. How should we screen for breast cancer? Mammography, ultrasonography, MRI. Cleve Clin J Med. 2007 Dec;74(12):897-904.

5. Hamill J, Campbell ID, Mayall F, Bartlett AS, Darlington A. Improved breast cytology results with near patient FNA diagnosis. Acta Cytol. 2002 Jan-Feb;46(1):19-24.

6. $\quad$ Esteller M. Epigenetics in cancer. N Engl J Med. 2008 Mar 13;358(11):1148-59.

7. Esteller M. Cancer epigenomics: DNA methylomes and histone-modification maps. Nat Rev Genet. 2007 Apr;8(4):286-98.

8. Hinshelwood RA, Clark SJ. Breast cancer epigenetics: normal human mammary epithelial cells as a model system. J Mol Med. 2008 Dec;86(12):1315-28.

9. Liu JW, Nagpal JK, Jeronimo C, Lee JE, Henrique R, Kim MS, et al. Hypermethylation of MCAM gene is associated with advanced tumor stage in prostate cancer. Prostate. 2008 Mar 1;68(4):418-26.

10. Lo PK, Sukumar S. Epigenomics and breast cancer. Pharmacogenomics. 2008 Dec;9(12):1879-902.

11. Page DL AT, Sakamoto G Infiltrating carcinoma: major histological types.

ed: Churchill-Livingstone, Edinburgh; 1987.

12. Elston CW El. Assessment of histological grade. Edinburgh: Churchill Livingstone; 1998.

13. Greene FL PD, Fleming ID, et al AJCC cancer staging manual. 6th ed. New York: Springer; 2002.

14. Clark SJ, Harrison J, Paul CL, Frommer M. High sensitivity mapping of methylated cytosines. Nucleic Acids Res. 1994 Aug 11;22(15):2990-7.

15. Eads CA, Danenberg KD, Kawakami K, Saltz LB, Blake C, Shibata D, et al. MethyLight: a high-throughput assay to measure DNA methylation. Nucleic Acids Res. 2000 Apr 15;28(8):E32.

16. Lehmann U, Langer F, Feist H, Glockner S, Hasemeier B, Kreipe H. Quantitative assessment of promoter hypermethylation during breast cancer development. Am J Pathol. 2002 Feb;160(2):605-12.

17. Jeronimo C, Henrique R, Hoque MO, Ribeiro FR, Oliveira J, Fonseca D, et al. Quantitative RARbeta2 hypermethylation: a promising prostate cancer marker. Clin Cancer Res. 2004 Jun 15;10(12 Pt 1):4010-4.

18. Henrique R, Ribeiro FR, Fonseca D, Hoque MO, Carvalho AL, Costa VL, et al. High promoter methylation levels of APC predict poor prognosis in sextant biopsies from prostate cancer patients. Clin Cancer Res. 2007 Oct 15;13(20):6122-9.

19. Pu RT, Laitala LE, Alli PM, Fackler MJ, Sukumar S, Clark DP. Methylation profiling of benign and malignant breast lesions and its application to cytopathology. Mod Pathol. 2003 Nov;16(11):1095-101.

20. Dulaimi E, Hillinck J, Ibanez de Caceres I, Al-Saleem T, Cairns P. Tumor suppressor gene promoter hypermethylation in serum of breast cancer patients. Clin Cancer Res. 2004 Sep 15;10(18 Pt 1):6189-93.

21. Bardou VJ, Arpino G, Elledge RM, Osborne CK, Clark GM. Progesterone receptor status significantly improves outcome prediction over estrogen receptor status alone for 
adjuvant endocrine therapy in two large breast cancer databases. J Clin Oncol. 2003 May 15;21(10):1973-9.

22. Euhus DM, Bu D, Milchgrub S, Xie XJ, Bian A, Leitch AM, et al. DNA methylation in benign breast epithelium in relation to age and breast cancer risk. Cancer Epidemiol Biomarkers Prev. 2008 May;17(5):1051-9.

23. Van der Auwera I, Bovie C, Svensson C, Trinh XB, Limame R, van Dam P, et al. Quantitative methylation profiling in tumor and matched morphologically normal tissues from breast cancer patients. BMC Cancer. 2010;10:97.

24. Jin Z, Tamura G, Tsuchiya T, Sakata K, Kashiwaba M, Osakabe M, et al. Adenomatous polyposis coli (APC) gene promoter hypermethylation in primary breast cancers. Br J Cancer. 2001 Jul 6;85(1):69-73.

25. Muller HM, Widschwendter A, Fiegl H, Ivarsson L, Goebel G, Perkmann E, et al. DNA methylation in serum of breast cancer patients: an independent prognostic marker. Cancer Res. 2003 Nov 15;63(22):7641-5.

26. Hoque MO, Feng Q, Toure P, Dem A, Critchlow CW, Hawes SE, et al. Detection of aberrant methylation of four genes in plasma DNA for the detection of breast cancer. $\mathrm{J}$ Clin Oncol. 2006 Sep 10;24(26):4262-9. 


\section{Figure Legends:}

Figure 1 - Receiver Operator Characteristic (ROC) curve for each individual gene (APC, RASSF1A and CCND2) in FNA washings from breast lesions

Figure 2 - Receiver Operator Characteristic (ROC) curve for each individual gene (APC, RASSF1A and CCND2) in FNA washings from breast lesions: (A) for premenopausal women; (B) for postmenopausal women.

Figure 3 - Disease-specific survival curve based on pathological stage in FNA washings from the 165 breast cancer patients.

Figure 4 - Disease-specific survival curve based on tumor grade in FNA washings from the 165 breast cancer patients.

Figure 5 - Disease-free survival curve based on RASSF1A high-methylation levels in FNA washings from the 165 breast cancer patients. Abbreviations: P75, percentile 75 of promoter methylation level.

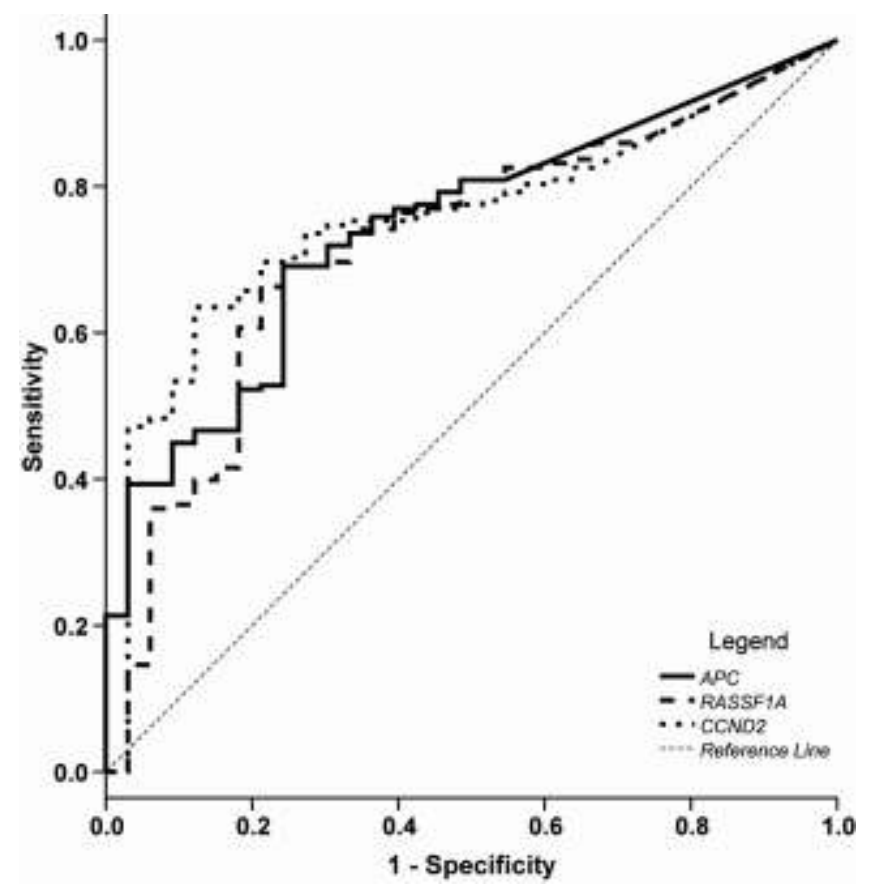



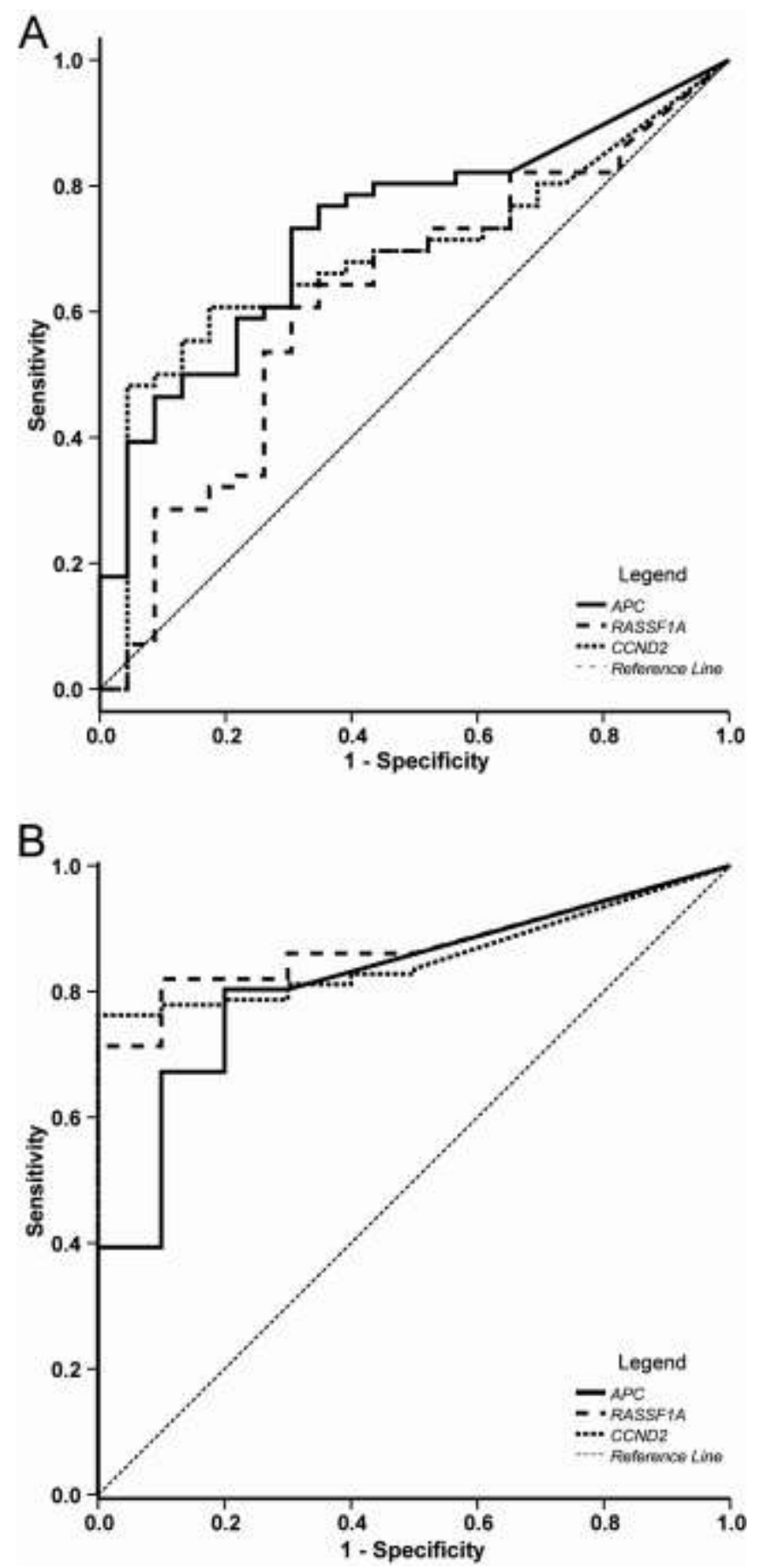

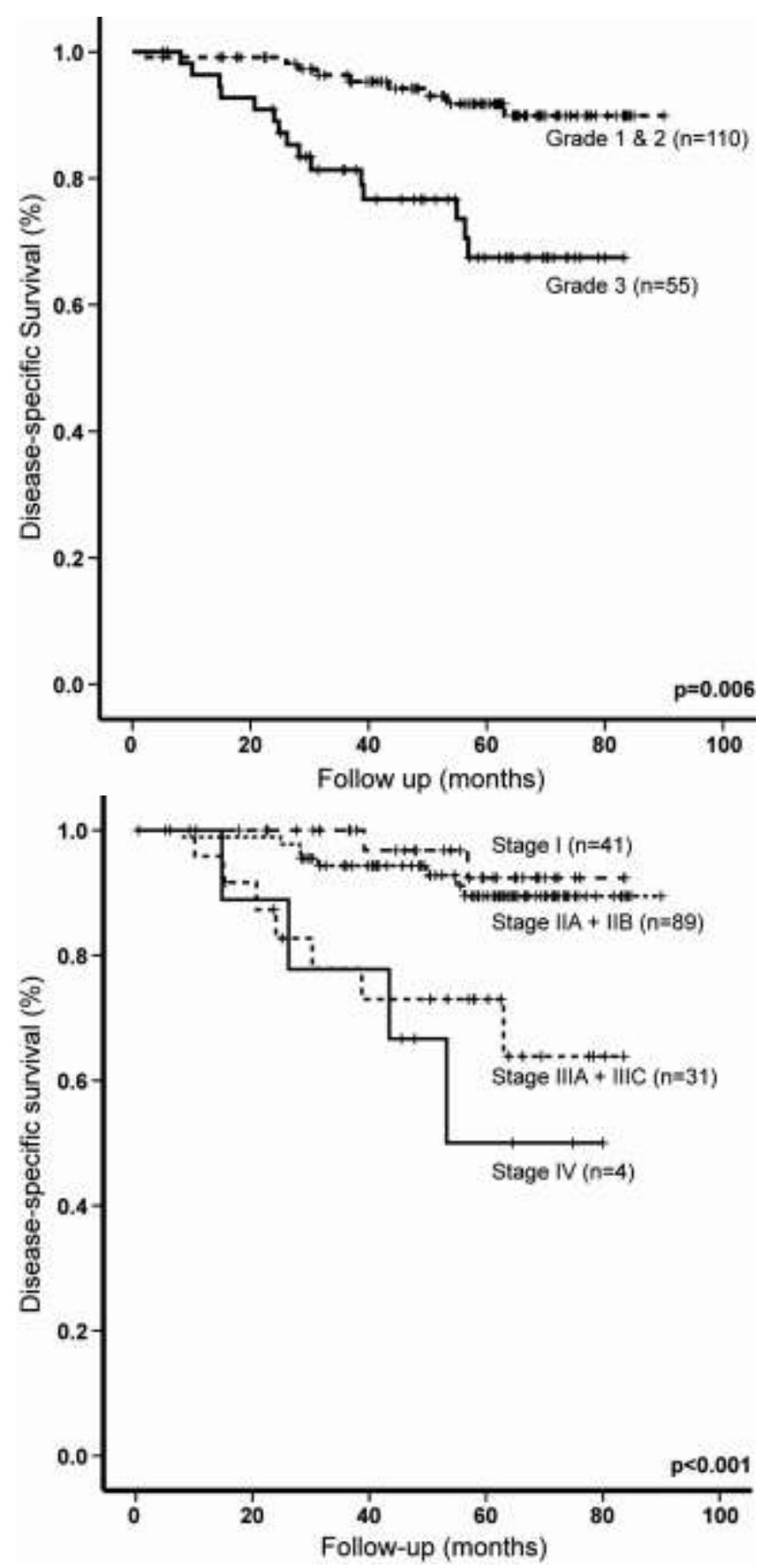


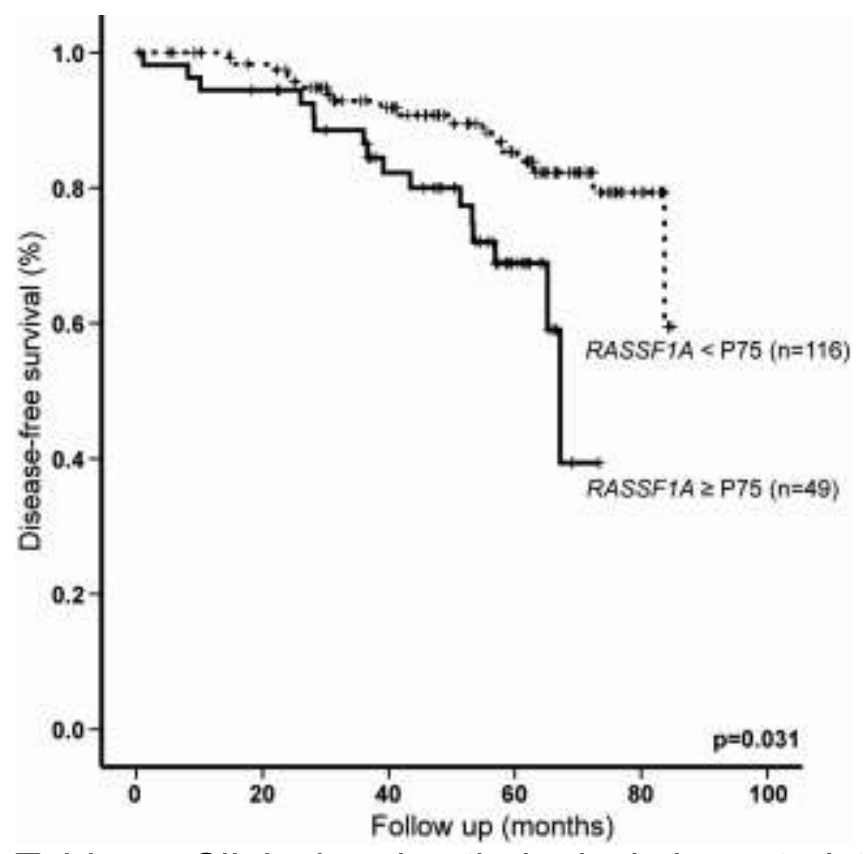

Table 1 - Clinical and pathological characteristics of patient's populations

Malignant

Benign

Patients $(n)$

178

33

Age, years, median (range)

$62(29-92)$

$42(18-77)$

Tumor size, $\mathrm{cm}$, median (range)

$2.5(0.45-9.5)$

n.a.

Histopathologic classification

n.a.

Carcinoma in situ 3

Invasive ductal carcinoma 135

Invasive lobular carcinoma

Mixed and special types of carcinoma

Grade, $n(\%)$

n.a.

1

2

84

3

Not determined

6

Stage, $n(\%)$

n.a.

0 
IV

Not determined

Hormonal Receptor status
4

5

n.a.

$\mathrm{ER}+$ 142

ER 33

Not determined 3

$\mathrm{PgR}+$ 113

$\mathrm{PgR}$ 62

Not determined 3

* n.a.: Non applicable

Table 2 - Frequency of positive cases [n (\%)] and distribution of methylation levels of cancerrelated genes [gene/ACTBx1000:median (IQR)]

\begin{tabular}{lccccc}
\hline & \multicolumn{2}{c}{ Benign } & \multicolumn{2}{c}{ Malignant } & \\
\cline { 2 - 5 } Gene & $\mathbf{n}(\%)$ & Median (IQR) & $\mathbf{n}(\%)$ & Median (IQR) & P value* \\
\hline APC & $18(55 \%)$ & $0.12(0-25.8)$ & $144(81 \%)$ & $86.85(1.41-723.78)$ & $<0.001$ \\
CCND2 & $22(67 \%)$ & $1.30(0-11.0)$ & $147(83 \%)$ & $86.77(3.41-474.46)$ & $<0.001$ \\
RASSF1A & $24(73 \%)$ & $14.49(0-177.59)$ & $153(86 \%)$ & $482.50(52-2125.33)$ & $<0.001$ \\
\hline
\end{tabular}

IQR, interquartile range

Table 3 - Validity estimates for increasing number of positive tested markers in the validation dataset of fine-needle aspirate washings from breast lesions (Se: sensitivity; Sp: specificity, $\mathrm{LR}+$ : positive likelihood ratio, PV+: positive predictive value, LR-: negative likelihood ratio, PV-: negative predictive value, AUC. Area under curve, $\alpha$ : estimated added information).

Number of markers with positive result in each case 


\begin{tabular}{lccc}
\hline Se $(95 \% \mathrm{Cl})$ & $0.88(0.82-0.92)$ & $0.78(0.71-0.83)$ & $0.37(0.30-0.44)$ \\
Sp $(95 \% \mathrm{Cl})$ & $0.42(0.24-0.62)$ & $0.79(0.62-0.89)$ & $0.91(0.76-0.97)$ \\
LR+ $(95 \% \mathrm{Cl})$ & $1.50(1.078-2.12)$ & $3.65(1.88-7.09)$ & $4.08(1.37-12.20)$ \\
$\mathrm{PV}+(95 \% \mathrm{Cl})$ & $0.89(0.85-0.94)$ & $0.93(0.89-0.96)$ & $0.96(0.93-0.98)$ \\
LR- $(95 \% \mathrm{Cl})$ & $0.29(0.17-0.54)$ & $0.28(0.21-0.39)$ & $0.69(0.59-0.81)$ \\
PV - $(95 \% \mathrm{Cl})$ & $0.54(0.47-0.61)$ & $0.35(0.28-0.41)$ & $0.24(0.18-0.30)$ \\
AUC $(95 \% \mathrm{Cl})$ & $0.75(0.70-0.81)$ & $0.85(0.81-0.90)$ & $0.77(0.71-0.83)$ \\
Added information & & & \\
a (95\% Cl) & $0.51(0.44-0.58)$ & $0.71(0.65-0.77)$ & $0.54(0.47-0.60)$ \\
\hline
\end{tabular}

Table 4 - Distribution of gene promoter methylation levels and frequencies according to clinical and pathological parameters in breast cancers

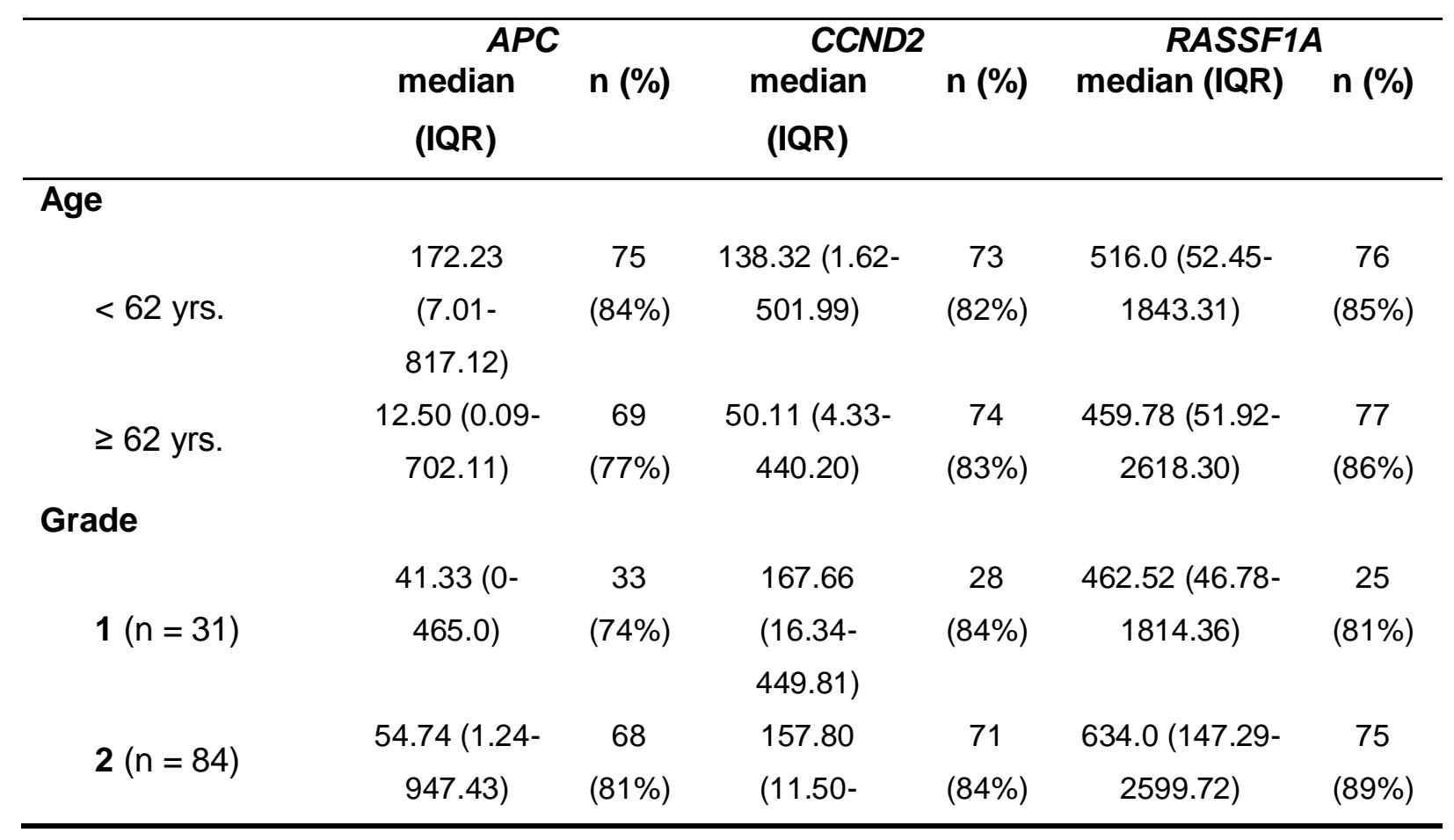




\begin{tabular}{lcccccc}
\hline & & & $559.14)$ & & & \\
3 $(\mathrm{n}=57)$ & 240.56 & 49 & $38.41(0.72-$ & 47 & $354.14(14.19-$ & 48 \\
& $(3.81-$ & $(86 \%)$ & $501.99)$ & $(82 \%)$ & $2141.44)$ & $(84 \%)$ \\
Stage & $892.83)$ & & & & & \\
& & & & & & \\
I $(\mathrm{n}=41)$ & $18.95(0.01-$ & 31 & 206.47 & 15 & $408.58(108.28-$ & 39 \\
& $403.29)$ & $(76 \%)$ & $(24.07-$ & $(85 \%)$ & $2341.60)$ & $(95 \%)$ \\
II $(\mathrm{n}=90)$ & 115.38 & 73 & $85.07(1.19-$ & 73 & $469.63(24.44-$ & 73 \\
& $(1.41-$ & $(81 \%)$ & $501.0)$ & $(81 \%)$ & $1839.15)$ & $(81 \%)$ \\
III $(\mathrm{n}=35)$ & $690.13)$ & & & & & 30 \\
& 331.05 & 31 & $50.91(1.34-$ & 29 & $744.69(183.31-$ & 30 \\
& $(7.59-$ & $(89 \%)$ & $380.59)$ & $(83 \%)$ & $2695.73)$ & $(86 \%)$ \\
IV $(\mathrm{n}=4)$ & $1089.66)$ & & & & & \\
& 778.89 & 3 & 120.45 & 3 & 1827.79 & 3 \\
& $(0.75-$ & $(75 \%)$ & $(49.73-$ & $(75 \%)$ & $(538.34-$ & $(75 \%)$ \\
& $3045.21)$ & & $197.75)$ & & $3945.27)$ &
\end{tabular}

\section{Estrogen receptor}

status

$\begin{array}{ccccccc} & 140.28 & 118 & 191.28 & 122 & 622.98(77.49- & 128 \\ \mathbf{E R}+(\mathrm{n}=142) & (1.55- & (83 \%) & (19.22- & (86 \%) & 2566.22)^{\star * \star} & (90 \%) \\ & 875.94) & & 548.39)^{\star} & & & \\ \mathbf{E R}-(\mathrm{n}=33) & 8.08(0- & 24 & 3.92(0- & 24 & 32.67(0- & 22 \\ & 368.48) & (73 \%) & 67.07)^{*} & (73 \%) & 1693.97)^{\star \star *} & (67 \%)\end{array}$

\section{Progesterone}

receptor status

$\begin{array}{ccccccc} & 110.12 & 91 & 180.36 & 97 & 479.49(108.96- & 99 \\ \mathbf{P g R}+(\mathrm{n}=113) & (1.21- & (80 \%) & (18.26- & (86 \%) & 2492.85) & (88 \%) \\ & 702.11) & & 522.07)^{\star *} & & & \\ \mathbf{P g R}-(\mathrm{n}=62) & 64.0(1.46- & 50 & 33.94(0.50- & 48 & 624.29(26.14- & 50 \\ & 859.58) & (82 \%) & 256.58)^{\star *} & (79 \%) & 2141.44) & (82 \%)\end{array}$

IQR: interquartile range (p25-p75); Statistically significant differences: ${ }^{*} \mathrm{P}<0.001 ;{ }^{* *} \mathrm{P}=0.011 ;{ }^{* *} \mathrm{P}=$ 0.003

Table 5 - Cox regression models assessing the potential of clinical and epigenetic variables in the prediction of overall survival, disease-specific or disease-free survival for 165 breast cancer patients 


\begin{tabular}{ccccc}
\hline Overall Survival & pTNM & 1.37 & $1.12-1.67$ & 0.002 \\
\hline $\begin{array}{c}\text { Disease-specific } \\
\text { Survival }\end{array}$ & pTNM & 1.51 & $1.19-1.92$ & $<0.001$ \\
\hline $\begin{array}{c}\text { Gisease-free } \\
\text { Survival }\end{array}$ & pTNM & 1.71 & $1.45-9.51$ & 0.006 \\
\hline $\begin{array}{c}\text { GASSF1A } \\
\text { methylation } \geq \mathrm{p75}\end{array}$ & 3.26 & $1.16-1.80$ & 0.001 \\
& 2.53 & $1.42-7.50$ & 0.005 \\
\hline
\end{tabular}

${ }^{*} \mathrm{Cl}$ : Confidence Interval 